\title{
Article \\ Phylogenetics and Biogeography of Lilium ledebourii from the Hyrcanian Forest
}

\author{
Shekoofeh Shokrollahi ${ }^{1}$, Hamed Yousefzadeh ${ }^{2,3, *}$, Christian Parisod ${ }^{4}$, Gholamali Heshmati ${ }^{1}$, Hamid Bina ${ }^{3}$, \\ Shujait Ali ${ }^{5}{ }^{\infty}$, Narjes Amirchakhmaghi ${ }^{3}$ and Yigang Song ${ }^{6, *}$
}

check for

updates

Citation: Shokrollahi, S.;

Yousefzadeh, H.; Parisod, C.;

Heshmati, G.; Bina, H.; Ali, S.;

Amirchakhmaghi, N.; Song, Y.

Phylogenetics and Biogeography of

Lilium ledebourii from the Hyrcanian

Forest. Diversity 2022, 14, 137.

https://doi.org/10.3390/d14020137

Academic Editors: Mario A. Pagnotta and Michael Wink

Received: 24 November 2021

Accepted: 9 February 2022

Published: 15 February 2022

Publisher's Note: MDPI stays neutral with regard to jurisdictional claims in published maps and institutional affiliations.

Copyright: (C) 2022 by the authors. Licensee MDPI, Basel, Switzerland. This article is an open access article distributed under the terms and conditions of the Creative Commons Attribution (CC BY) license (https:// creativecommons.org/licenses/by/ $4.0 /)$.
1 Department of Rangeland, Gorgan University of Agricultural Sciences and Natural Resources, Gorgan 49138-15749, Iran; shokrollahi.sh93@yahoo.com (S.S.); heshmati@gau.ac.ir (G.H.)

2 Department of Environment, Faculty of Natural Resources, Tarbiat Modares University, Tehran 14115-111, Iran

3 Department of Forestry, Faculty of Natural Resources, Tarbiat Modares University, Tehran 14115-111, Iran; hamid.bina@ymail.com (H.B.); n_amirchakhmaghi@yahoo.com (N.A.)

4 Institute of Plant Sciences, University of Bern, Altenbergrain 21, CH-3013 Bern, Switzerland; christian.parisod@ips.unibe.ch

5 Center for Biotechnology and Microbiology (CBM), University of Swat, Odigram, Mingora 19130, Pakistan; shujaitswati@yahoo.com

6 Eastern China Conservation Centre for Wild Endangered Plant Resources, Shanghai Chenshan Botanical Garden, Shanghai 201602, China

* Correspondence: h.yousefzadeh@modares.ac.ir (H.Y.); ygsong@cemps.ac.cn (Y.S.)

\begin{abstract}
Lilium ledebourii (Baker) Boiss is one of the most endangered lilies, restricted to only a few small and fragmented areas in the Hyrcanian forest. This study aimed at evaluating the taxonomy of this unique Iranian lily and reconstructing divergence time from other species of the genus Lilium to address the role of this region in its diversification. Phylogenetic trees based on nuclear ITS and chloroplastic matK strongly supported the monophyly of the genus Lilium and division into subclades hardly matching prior morphological classifications. Biogeographic analyses using S-DIVA revealed East Asia as the ancestral range from where Lilium presented a multidirectional expansion towards North America, West-Central Asia, North Asia, and Europe. Diverging from ancestral Lilium during the beginning of Eocene (50 Ma; 95\% HDP: 68.8-36.8). Specific members of Lilium colonized Iran (Western Asia) separated from the Clade IV (West-Central Asia and Europe lineage), and then yielded the Iranian L. ledebourri. Accordingly, the north of Iran appears to have promoted both long-term persistence and migration of Lily species from Asia to the Europe.
\end{abstract}

Keywords: phylogeny; biogeography; divergence; critically endangered; rare species

\section{Introduction}

Lilium L. (Liliaceae) is one of the most fascinating genera among the plant kingdom, and it adds to its importance on horticulture, medicine and food [1-3]. Lilium is a perennial herbs with subterranean bulbs and mostly spring-flowering that grow in steppes and mountain meadows [4]. This genus occurs in Eurasia and North America and has three main ranges including the Qinghai-Tibetan Plateau in East Asia, North America, and the Caucasus [5,6]. The genus of Lilium, with approximately 100 species, has been classified into five to eleven sections [7-9]. Due to the frequent gene flow among sections, the major phylogenetic clades of Lilium are still controversial but have been clear $[2,3,8,10]$. Traditionally, seven sections were recognized based on morphological taxonomy and molecular phylogenetic methods $[2,8,10]$.

The Hyrcanian area in the southern shores of the Caspian Sea presents remnants of natural deciduous forests [11] and forms a unique vegetation belt from the Talish region in Azerbaijan to Golestan National Park in Iran (between $48^{\circ}-56^{\circ}$ E and $38^{\circ} 55^{\prime}-35^{\circ} 05^{\prime} \mathrm{N}$ ) [12] Decreasing water levels during the Quaternary, coupled with the rising of the Earth's 
crust in the northern Caucasus, led to the separation of the Black Sea and the Caspian Sea, promoting the isolation of the Hyrcanian region [13]. The presence of many Arcto-Tertiary relict species in the area was generally viewed as coherent with the Hyrcanian forest having acted as major refugia sheltering the long-term persistence of plant species [14,15]. To confirm this hypothesis, additional data are necessary.

Lilium ledebourii (Baker) Boiss (Iranian lily) is a rare and endemic lily species distributed only in a few small areas of the Hyrcanian forest [16]. Its habitat was recorded as a natural monument in Iran's protected areas in 1976 [17]. This species is attractive and widely used in ornamental breeding programs, and some biochemical features were also studied [18,19]. Limited information is available regarding its phylogenetic position; however, there was one recent study based on the nuclear rDNA-internal transcribed spacers (ITS) and another based on the $5.8 \mathrm{~S}$ ribosomal DNA sequence $[19,20]$. However, due to the incomplete sampling on the distribution range of L. ledebourii and single sequence, its phylogenetic position is still unclear. Furthermore, there are several biogeographic studies of the genus Lilium missing this species. As the famous species is restricted to the biodiversity hotspots, L. ledebourii presents a less known biogeographic synthesis, and deserves further attention [21,22].

Despite the advent of genomics, DNA barcoding based on nucleotide sequences from variable chloroplastic and nuclear loci is still facilitated to monitor the phylogenetic position accurately and economically [23-25]. Here, we thus address the phylogenetic position of L. ledebourii concerning worldwide Lilium species and shed light on its role for the biogeography and diversification of the genus. The first purpose of this study is to present the phylogenetic relationships of the Iranian Lily based on nuclear and plastid DNA markers; the second goal is to estimate the divergence time of the Iranian Lily and discuss the biogeography of Lilium after adding the Iranian Lily.

\section{Materials and Methods}

\subsection{Sampling and DNA Extraction}

Leaf samples of L. ledebourii were collected from four natural populations (all reported sites for this species) of the Hyrcanian forest (Figure 1). Total genomic DNA was extracted from at least 10 individuals from each population following Murray and Thompson (1980), with modifications according to Janfaza et al. [26].

\subsection{PCR Amplification and Sequencing}

For amplification and sequencing, four candidate DNA barcoding regions were selected: the internal transcribed spacer regions (ITS) from nuclear genomes and three plastid regions (matK, trnL-F and psbA-trnH). PCR amplifications were performed in $20 \mu \mathrm{L}$ using the AccuPower HotStart PCR PreMix kit (Bioneer, Daejeon, Korea), with either universal ITS-1 and ITS-4 primers from White et al. [27] or matK primers from Johnson et al. [28] or primers for the trnL-F intergenic spacer from Taberlet et al. [29] or primers for the psbA-trnH intergenic spacer from Sang et al. [30]. For ITS, psbA-trnH and trnL-F regions, PCR cycles consisted of an initial denaturation for $6 \mathrm{~min}$ at $95^{\circ} \mathrm{C}$, followed by 32 cycles of $60 \mathrm{~s}$ at $95{ }^{\circ} \mathrm{C}, 45 \mathrm{~s}$ at $56^{\circ} \mathrm{C}, 90 \mathrm{~s}$ at $72{ }^{\circ} \mathrm{C}$, and a final extension of $5 \mathrm{~min} 72{ }^{\circ} \mathrm{C}$. The matK region was amplified following Hayashi and Kawano (2000) [31], including 35 cycles of $60 \mathrm{~s}$ at $94{ }^{\circ} \mathrm{C}, 120 \mathrm{~s}$ at $50{ }^{\circ} \mathrm{C}, 180 \mathrm{~s}$ at $72{ }^{\circ} \mathrm{C}$ and a final extension at for $7 \mathrm{~min}$ at $72{ }^{\circ} \mathrm{C}$ ). After a check through electrophoresis, $\mathrm{PCR}$ products were sent to Bioneer service (Bioneer, Daejeon, Korea) for sequencing, and the resulting electropherograms were manually inspected using Chromas version 2.3 (www.technelysium.com.au (15 February 2020) to yield accurate sequence data. 


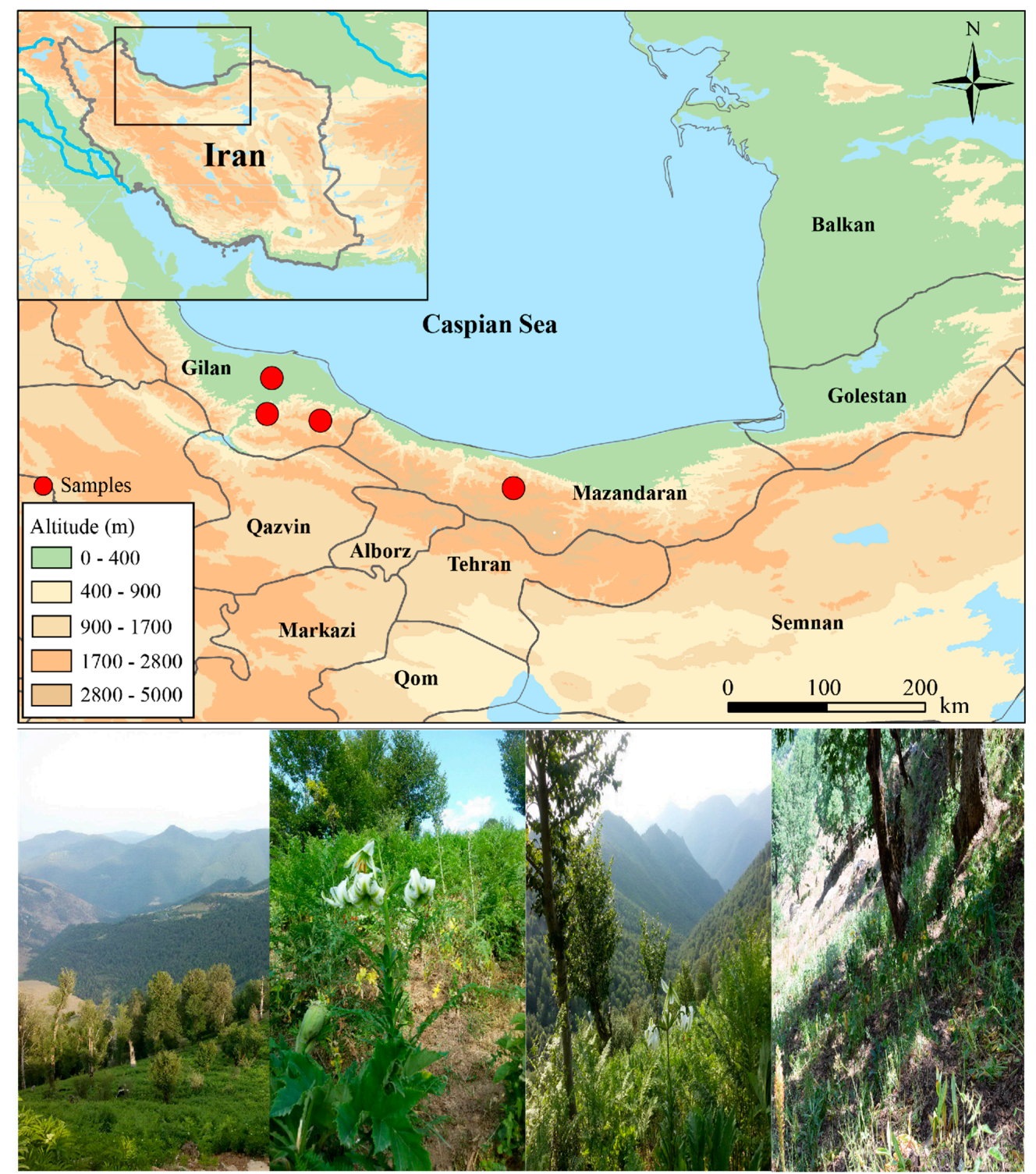

Figure 1. Geographical sampling sites of Lilium ledebourii in the Hyrcanian forest, part of Iran.

\subsection{Phylogenetic Analysis and ITS2 Secondary Structure}

There are eight individuals of L. ledebourii were used in the phylogenetic analysis in this study. The analysis based on ITS sequences used 35 Lilium species and took five Tulipa species as outgroups. The analysis based on matK sequences used 21 Lilium species and taken two Tulipa species as outgroups.

Alignments of sequences were performed for each locus using MUSCLE and nucleotide composition, the number of variables, parsimony and conserved sites among studied taxa were estimated in MEGA 6 [32]. A median-joining (MJ) network was inferred from all variable characters of the complete alignment of concatenated sequences using NETWORK 3.1.1.1 [33]. The phylogenetic tree was constructed based on maximum likelihood (ML) and Bayesian inference (BI) for all taxa.

Bayesian inference tree was constructed by MrBayes v. 3.2.6 with a cold chain and three incrementally heated chains $(T=0.2)$, running for $10,000,000$ generations with a sampling frequency of 1000 . The first $25 \%$ of the trees were discarded (burnin) and the remaining trees were used to build a consensus tree and estimate Bayesian posterior probabilities. The MEGA (version 6) [32] software was used to choose the best model and create phylogenetic trees using maximum likelihood (ML) methods, [34]. Bootstrap analysis with 1000 replications was used to analyze the reliability of each branch. ITS2 secondary 
structure for each taxon was inferred by minimizing free energy and homology search across the ITS2 database (http:/ /its2.bioapps.biozentrum.uni-wuerzburg.de/ (27 February 2020).

\subsection{Divergence Time Estimate and Biogeographic Analysis}

To estimate the divergence time of Lilium and reconstruct the ancestral geographical range of this genus, we used 31 Lilium species covering its entire distribution area. Partition homogeneity or incongruence length difference (ILD) [35] test was conducted in PAUP $\mathrm{v} 4.0 \mathrm{~b} 10$ [36] following a heuristic search approach of 1000 replicates with 100 random stepwise additions and tree bisection reconstruction (TBR) branch swapping supported congruity of ITS and matK datasets $(p=0.68)$. Similarly, the likelihood ratio test (LRT) carried out in PAUP v4.0b10 [36] supported a relaxed molecular clock approach for our combined dataset $(p=0.00001)$.

Divergence times were estimated by calibrating the stem node of Ripogonaceae, Luzuriaga, according to Kim and Kim (2018) [37], and the crown node of Smilax (the outgroup) to a mean age of 55 million years ago (Ma), 24 Ma and 46 Ma respectively, using the log-normal distribution prior with standard deviation of 1.0. The phylogenetic analysis was conducted for 50,000,000 generations using BEAST ver. 1.6.1 [38] under uncorrelated lognormal relaxed clock parameter and the Yule model of speciation as tree prior. The GTR + G substitution model was selected as the best fit model using jModel test under Akaike's information criterion (AIC). Tree Annotatorver.1.7.5 [39] and FigTreever.1.4 [40] were used for the generation and visualization of the maximum clade credibility tree.

The distribution of Lilium was divided into six regions based on the available samples: A (East Asia), B (North Asia), C (West and Central Asia), D (Europe), E (North America), and F (South America). Reconstruct Ancestral State in Phylogenies (RASP) software [41] was used for biogeographic inferences using Statistical Dispersal-Vicariance Analysis (S-DIVA) approaches. To overcome uncertainties associated with S-DIVA analysis out of 10,000 trees from BEAST, the maximum clade credibility tree and distribution file were uploaded into the RASP software for biogeographic reconstructions. In the BBM analysis, only the maximum clade credibility tree was used along with the distribution file to obtain a reconstruction and the Markov chain Monte Carlo (MCMC) was run under the JC + G (Jukes-Cantor + Gamma) model for 5,000,000 generations.

\section{Results}

\subsection{ITS and Plastid Regions (MatK, TrnL-F and TrnH-PsbA)}

The nucleotide composition of the Iranian samples of L. ledebourii from four different regions is summarized and compared with available samples of lilies in Table 1. ITS sequences from Iranian samples were longer (644-654 bp) than those retrieved from NCBI (465-485 bp). The matK region showed low variability among Lilium species (length $=853-881 \mathrm{bp}$, conserved sites $=849$ ). Iranian samples presented 19 variable sites, including nine singletons, whereas species available in NCBI presented 36 variable sites. The trnL-F and trnH-psbA regions showed the high conservation sites (length $=270-255$, conserved sites $=246$ ) and nucleotide percent of Temin (Iranian sample $=34.5$, sample from NCBI = 35.5). 
Table 1. Sequences characterization and nucleotide composition four regions trnH-psbA, trnL-F, matK and ITS without the outgroups.

\begin{tabular}{|c|c|c|c|c|c|c|c|c|c|c|c|}
\hline & Region & $\begin{array}{c}\text { Conserved } \\
\text { Sites }\end{array}$ & $\begin{array}{l}\text { Variable } \\
\text { Sites }\end{array}$ & $\begin{array}{l}\text { Parsim In- } \\
\text { formative } \\
\text { Sites }\end{array}$ & $\begin{array}{l}\text { Singleton } \\
\text { Sites }\end{array}$ & $\begin{array}{l}\text { Length } \\
\text { (bp) }\end{array}$ & $\mathrm{A} \%$ & $\mathbf{T} \%$ & $\mathrm{C} \%$ & $\mathrm{G} \%$ & Model \\
\hline \multirow{3}{*}{$\begin{array}{l}\text { Iranian } \\
\text { Sample }\end{array}$} & ITS & 549 & 80 & 27 & 52 & $644-654$ & 18.8 & 21.1 & 27.2 & 32.9 & $\mathrm{~T} 93+\mathrm{G}$ \\
\hline & $\begin{array}{l}\text { trnH- } \\
\text { psbA }\end{array}$ & 190 & 244 & 10 & 234 & $465-485$ & 36.8 & 38.7 & 16.5 & 18 & T92 \\
\hline & matk & 849 & 19 & - & 9 & $853-862$ & 31.1 & 38.5 & 15.8 & 14.6 & T92 \\
\hline \multirow{5}{*}{$\begin{array}{c}\text { Other } \\
\text { species }\end{array}$} & trnL-F & 246 & 13 & - & 13 & 270 & 30.5 & 34.5 & 18.5 & 16.6 & T92 \\
\hline & ITS & 436 & 171 & 108 & 63 & $644-660$ & 18.4 & 20.7 & 27.8 & 33 & $\mathrm{~T} 93+\mathrm{G}$ \\
\hline & $\begin{array}{l}\text { trnH- } \\
\text { psbA }\end{array}$ & 251 & 170 & 12 & 153 & $460-480$ & 31 & 36.1 & 15.9 & 17 & T92 \\
\hline & matk & 882 & 36 & 19 & 17 & $872-881$ & 31 & 38.6 & 15.8 & 14.6 & T92 \\
\hline & trnL-F & 255 & 4 & 2 & 2 & $260-270$ & 30.4 & 35.5 & 13.8 & 15.9 & T92 \\
\hline
\end{tabular}

\subsection{Phylogenetic Position of L. ledebourii}

Bayesian tree and ML trees based on ITS strongly supported a monophyletic genus Lilium and divided the species into six clades (Figure 2A), consistent with the MJ network (Supplementary Material Figure S1). These clades are somewhat consistent with the four main groups defined by Baker et al. [42] based on flower morphology: i.e., L. sect. Eulirion Rchb. (funnel-flowered lilies), L. sect. Archelirion Baker (open-flowered lilies), L. sect. Isolirion Baker (erect-flowered lilies) and L. sect. Martagon Rchb. (Turk's cap lilies). The results of the phylogenetic tree showed that the Caucasian and European species were placed in three separate clade (Figure 2A). All species of the European region were grouped in one clade, while seven species of the Caucasus were grouped in three separate clades. Surprisingly, L. ledebourii was placed in a clade with European species, and the L. ciliatum itself formed a separate clade, while other Caucasian species formed the third clade.

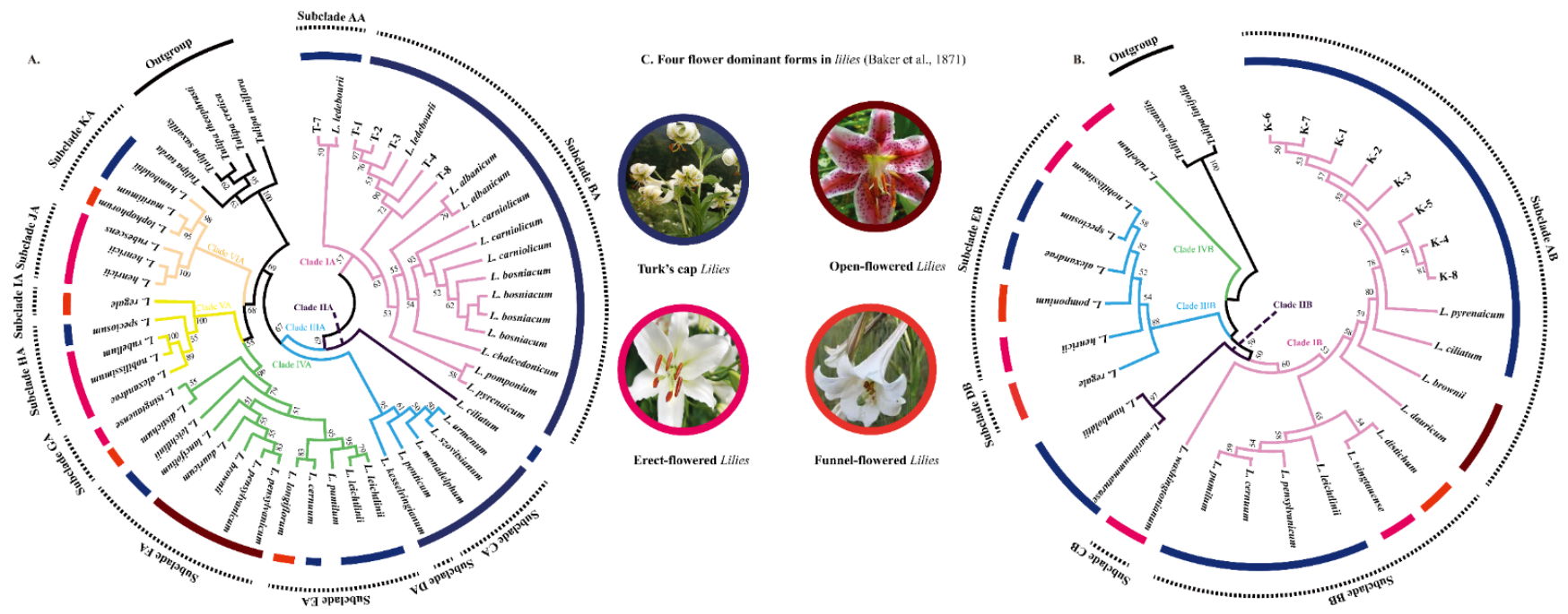

Figure 2. (A) Phylogenetic tree of Lilium based on ITS sequences (ITS1, 5.8 s, ITS2) with Maximum Likelihood method (model: Tumara3 parameter + Gamma distributed) and bootstrap 1000, (B) Phylogenetic tree of Lilium based on matK sequences with Maximum Likelihood method (model: Tumara3 parameter) and bootstrap 1000. ( $\mathrm{T}$ and $\mathrm{K}$ legends are represented repeated sequences of ITS and matK regions from the Hyrcanian forest, respectively). (C) Four morphological flower types of the genus Lilium based on classification of Baker et al., 1871).

The Bayesian matK tree has a backbone polytomy and four major lineages, with significant differences in composition between these lineages and the six resolved in the ITS phylogeny. The phylogenetic tree based on this region showed a high inconsistency 
with the Baker et al., 1871 classification, but divided all Hyrcanian specimens along with L. ciliatum from the Caucasus and L. pyrnaicum from Europe into one sub clade.

\subsection{Biogeography of the Genus Lilium}

The results of S-DIVA analyses suggest that the current distribution of Lilium species is the outcome of multiple dispersal and vicariance events (Figure 3). S-DIVA suggests 9 dispersal and three vicariance events. They congruently indicate that Lilium ancestors (node I) originated in East Asia, or East-West-Central Asia (Figure 3) at the beginning of Eocene (c.a. 50 MYA, 95\% HDP: 68.8-36.8, Table 2). Then, the ancestral Lilium from East Asia began to diverge into two clades (Clade II and Clade III) during the early and middle Eocene (Figure 3). During the Late Eocene and Oligocene, the Lilium began to spread to North America (Clade II) and West and Central Asia (Clade III). The Clade II have been included two obvious lineages (East Asia and North America lineage), and they carried out an independent evolution and diffusion from Miocene. In Clade III, the Lilium species in East Asia have four times the dispersal after Pliocene. Ancestral reconstructions of Clades IV and V further favor an ancestral range in western Asia and Europe (with 93.30\% and $78 \%$ marginal probability, respectively) in Clade III, including the Iranian L. ledebourri. Lilium ledebourii in West Asia looks like the first lineage separate from Clade IV.

Table 2. Age estimation in million year ago (MYA) of nodes of divergence time clade based on S-DIVA and BBM.

\begin{tabular}{ccccccccc}
\hline & \multicolumn{2}{c}{ Age Estimation (MYA) } & \multicolumn{2}{c}{ S-DIVA } & \multicolumn{2}{c}{ BBM } \\
\hline Nodes & Mean & 95\% HPDlower & 95\% HPDupper & AR & MP(\%) & AR & MP & Support (PP) \\
\hline I & 50.71 & 36.8 & 68.8 & A/AF & $49 / 36$ & A/AD & $60 / 16$ & 0.90 \\
II & 40.84 & 23.0 & 63.2 & AF & 99.71 & AF/A & $34 / 26$ & 0.80 \\
III & 40.45 & 28.2 & 56.5 & AC & 93.40 & A/AD & $42 / 23$ & 0.95 \\
IV & 33.25 & 20.5 & 49.8 & C & 93.30 & C/CD & $46 / 38$ & 1.00 \\
V & 27.08 & 15.7 & 44.0 & CD & 78.00 & C CD & $49 / 42$ & 0.90 \\
\hline
\end{tabular}

The overall scenario favored by S-DIVA (Table 3) supports stepping-stone radiation of the genus Lilium, with a primary center of diversification in eastern Asia (i.e., region A). Our inclusion of the Iranian samples here looks critical, as it supports an expansion and secondary diversification in western Asia (i.e., region C) before further range expansion and diversification towards Europe (i.e., region D).

Table 3. Dispersal details of different distribution area based on S-DIVA and BBM.

\begin{tabular}{|c|c|c|c|c|c|c|c|}
\hline \multicolumn{4}{|c|}{ S-DIVA } & \multicolumn{4}{|c|}{ BBM } \\
\hline $\begin{array}{l}\text { Distribution } \\
\text { Range }\end{array}$ & $\begin{array}{c}\text { Dispersal } \\
\text { from }\end{array}$ & Dispersal to & Within & $\begin{array}{c}\text { Distribution } \\
\text { Range }\end{array}$ & $\begin{array}{l}\text { Dispersal } \\
\text { from }\end{array}$ & Dispersal to & Within \\
\hline $\mathbf{A}$ & 44.00 & 0.00 & 28.0 & A & 64.0 & 0.00 & 28.0 \\
\hline B & 0.00 & 5.00 & 1.00 & B & 0.00 & 9.00 & 1.00 \\
\hline $\mathrm{C}$ & 2.00 & 5.00 & 8.00 & $\mathrm{C}$ & 2.00 & 7.00 & 9.00 \\
\hline D & 1.00 & 19.0 & 15.0 & $\mathrm{D}$ & 2.00 & 28.00 & 26.0 \\
\hline $\mathbf{E}$ & 0.00 & 3.00 & 0.00 & $\mathrm{E}$ & 0.00 & 4.00 & 0.00 \\
\hline $\mathbf{F}$ & 1.00 & 16.0 & 9.00 & $\mathrm{~F}$ & 4.00 & 24.00 & 18.0 \\
\hline
\end{tabular}




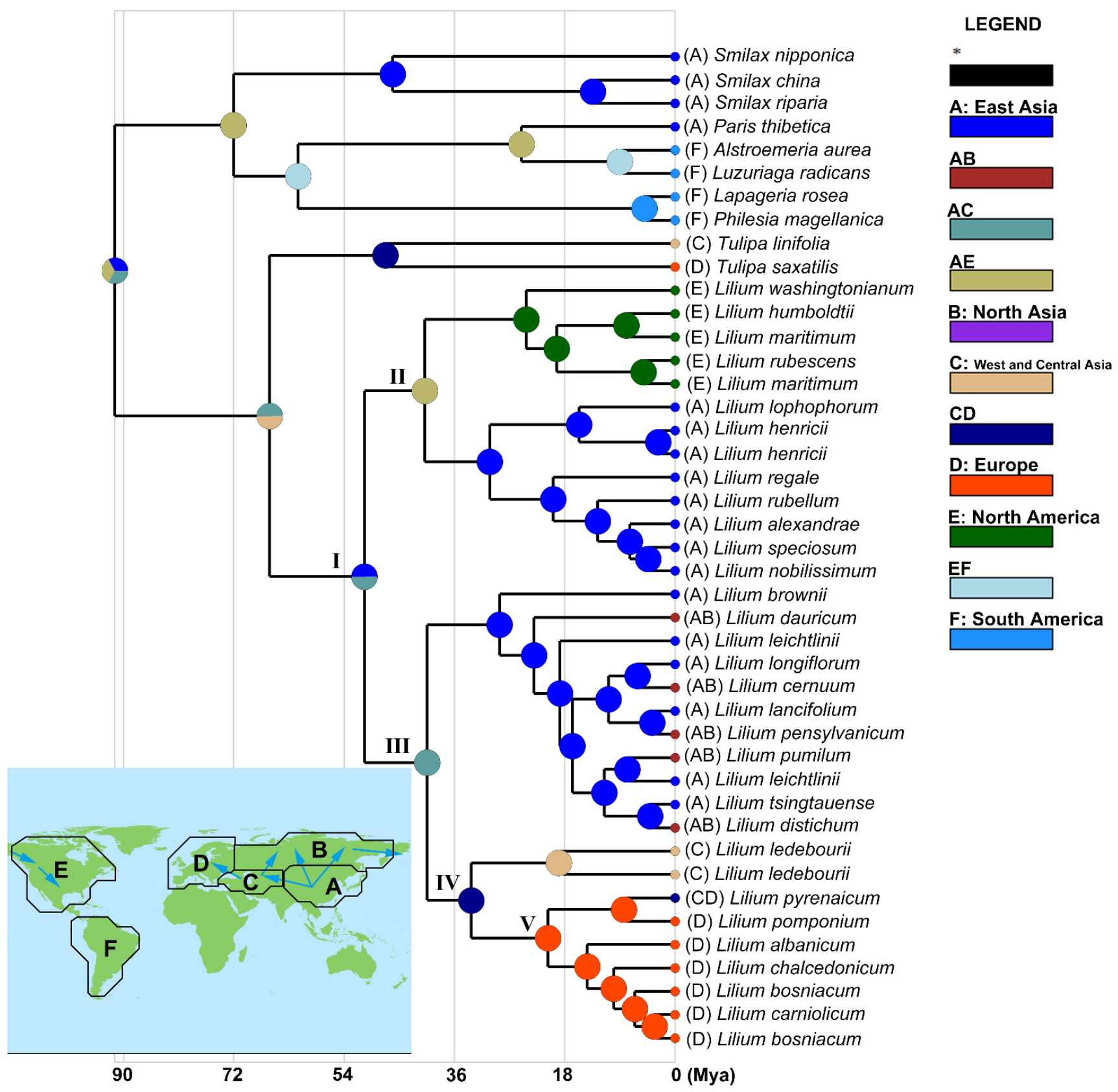

Figure 3. Divergence time estimations and the major divergence events among the Lilium species based on region combined data (ITS + matK regions) and Dispersal scenario of Lilium in the world. Pie charts depict ancestral area reconstruction probability, with the colors of pie slices defined in the legend. (The reader is directed to the web version of this article for an explanation of the color references in this figure legend).

\section{Discussion}

\subsection{Phylogeny and Biogeography of Lilies}

Our research sheds light on the natural divergence histories of L. ledebourii in the Caucasian Hyrcanian forest of Iran, which is a hotspot for biodiversity. The results showed that L. ledebourii from this region belonging to the Caucasians are older than the European samples, and thus Iran could be a bridge for transforming L. ledebourii into Europe. Furthermore, we discovered that the phylogenetic position of the Lilium genus did not follow the flower shape. 
Phylogenetic inferences based on ITS and matK loci here largely confirmed earliest classifications based on morphology to distinguish either five sections [9] or four main groups [42]. Iranian lilies (L. ledebourii), analyzed here for the first time, were closely related to European species (L. pyrenaicum) as well as species from Caucasus [43] to be part of the Martagon section composed of species forming mostly Turk's cap flowers.

The inclusion of the Iranian samples offers a comprehensive sampling with representative species from most regions colonized by lilies to bring fresh insights into their evolution. For instance, the controversial $L$. lophophorum here appears consistent with the classification of Wilson [44] in a Lophophorum subsection, whereas close relationships with L. humboldtii further supports an early origin out of Chinese lineages. All species comprised here in clade V (sections Archelirion and Martagon of Baker's classification) share an origin in east Asia and support Comber [8] classification. Although the impact of hybridization remains controversial in the genus Lilium [45], present results indicate close relationships between species of Sinomartagon and Archelirion sections, supporting the view of Leslie [46] about hybridization between corresponding species. In particular, L. henrici here is shown to be very close to $L$. alexandrae and these species may have undergone gene flow. However, inference of reticulate evolution across the genus Lilium is beyond the scope of this work.

\subsection{Biogeography of Lilium Emphasis on West Asia}

Even though Lilium is one of the most famous genera all over the world, the biogeographic study of this genus is limited [5]. Gao et al. (2013) tried to analyze the evolutionary events in Lilium. Due to the sampling, this study only focused on the biogeography of the Q-T plateau and the Hengduan Mountains. In this study, we try to cover the distribution area of the genus to explore the biogeography of this genus, adding some species from West Asia.

Biogeographic reconstructions using S-DIVA indicated an ancestral origin of Lilium in Eastern Asia or the extensive area of East-Central-West Asia during the Eocene around 50 MYA (95\% HDP: 68.8-36.8). This contrasts with prior dating based on the plastid dataset that concluded on a last common ancestor of Lilium some 13.19 MYA [5]. Thus, our results suggest that Lilium may have early origins in the Pan-Asian region. The genus began to spread outside of Asia during the Eocene. Two early radiation events from the ancestral area have particularly supported independent colonization toward Western Asia and towards North America. This event may have benefited from the warm climatic conditions in this Geologic period. This is in keeping with prior hypotheses of migration for diverse plants and animals between the Old and the New Worlds through either the North Atlantic Land Bridge (NALB) or Beringia [47], rather than the suggestion in some works of literature that the Himalayas were the center of origin of the genus Lilium [5,6]. This pattern also contrasts with the proposal of Ikinci et al. [48] that European species derive from multiple routes, with L. martagon first colonizing Europe, whereas a second route later gave rise to L. bulbiferum and further diversification of all other European species. Lilium species of Iran (Western Asia) indeed involved radiation of ancestors from East Asia to Europe, with early colonization of Western Asia from East Asia (50-40 MYA) followed by additional events some 20 MYA and 10 MYA. In particular, three radiations were apparent between Western Asia and Europe in our analysis, supporting dispersal from Western Asia to Europe during the Oligocene (28 MYA) and again during the Miocene (18 MYA).

Due to the limited impact of the ice ages during the Pleistocene, it indeed hosts an impressive number of endemic and relict species [49]. Our analysis showed that the rare Lilium ledebourii is such a relict species that currently scattered among small populations in cliffs above the tree line. These populations seemingly represent survivors of previously large populations having migrated to the area before the ice age. Accordingly, the northern forests of Iran likely acted as refugia for such species. The presence of tree species from typically high latitudes such as Betula pendula and Sorbus aucaparia in the Hyrcanian forest further corroborates the case of L. ledebourii. 
A non-mutually exclusive hypothesis is that the north of Iran represents a path for migration of species from East Asia to Europe during periods of drastic environmental changes. Khalilzadeh et al. [50] indeed concluded that the north west of Iran (specifically Southwest Caspian Sea) is a major contact zone between Asian and European clades of Wild Boar and biogeographic inferences on several plant species [51,52] supported the north of Iran (Hyrcanian forest) as a main corridor for plant migration between the East and the West of the Eurasian continent. As expressed by Manafzadeh et al. [53], the IranoTuranian floristic region can serve as a 'donor' of xerophytic taxa to 'recipient' neighboring regions, including the Mediterranean floristic region. Additional studies appear necessary to accurately quantify the refugial vs. corridor role of the Hyrcanian forest.

In conclusion, the phylogenetic position and biogeography of endemic lily species in the Hyrcanian forest were studied using the barcoding technique. The phylogenetic tree utilizing ITS rather than matK produced results that were more consistent with morphological classification and placed L. ledebourii in a phylogenetic group with other Caucasian species and section Liriotypus. The divergence time of L. ledebourii determined that L. ledebourii diverged from the radiation of ancestors in East Asia, and then formed a West-Central Asia and Europe lineage during the end of the Eocene. Accordingly, the north of Iran appears to act as long-term persistence and migration of Lily species from Asia to Europe.

Supplementary Materials: The following are available online at https://www.mdpi.com/article/10 .3390/d14020137/s1, Figure S1: Network tree of the genus Lilium based on ITS region (A) and mat K region (B).

Author Contributions: H.Y., G.H. and S.S. designed the study, H.Y. and S.S. collected the plant material, H.Y., H.B., S.A., N.A. and Y.S. performed analysis of data and H.Y., C.P. and Y.S. wrote the paper. All authors have read and agreed to the published version of the manuscript.

Funding: This research received no external funding.

Institutional Review Board Statement: Not applicable.

Informed Consent Statement: Not applicable.

Data Availability Statement: The data reported here are archived as Supplemental Material in PSE. Compliance with ethical standards.

Conflicts of Interest: The authors declare that they have no conflict of interest.

\section{References}

1. Woodcock, H.; Stearn, W.T. Lilies of the World, Their Cultivation and Classification; Country Life Limited: London, UK, 1950.

2. Gong, X.; Huang, H.H.; Ting, Y.W.; Hsu, T.W.; Malikova, L.; Tran, H.T.; Huang, C.L.; Liu, S.H.; Chiang, T.Y. Frequent gene flow blurred taxonomic boundaries of sections in Lilium L. (Liliaceae). PLoS ONE 2017, 12, e0183209. [CrossRef] [PubMed]

3. Kim, H.T.; Lim, K.B.; Kim, J.S. New insights on Lilium phylogeny based on a comparative phylogenomic study using complete plastome sequences. Plants 2019, 8, 547. [CrossRef] [PubMed]

4. Lee, C.S.; Kim, S.C.; Yeau, S.H. Major lineages of the genus Lilium (Liliaceae) based on nrDNA ITS sequences, with special emphasis on the Korean species. J. Plant Biol. 2011, 54, 159-171. [CrossRef]

5. Gao, Y.-D.; Harris, A.; Zhou, S.-D.; He, X.-J. Evolutionary events in Lilium (including Nomocharis, Liliaceae) are temporally correlated with orogenies of the Q-T plateau and the Hengduan Mountains. Mol. Phylogenet. Evol. 2013, 68, 443-460. [CrossRef]

6. Patterson, T.B.; Givnish, T.J. Phylogeny, concerted convergence, and phylogenetic niche conservatism in the core Liliales: Insights from rbcL and ndhF sequence data. Evolution 2002, 56, 233-252. [CrossRef]

7. Baranova, M. The lily species in the flora of the former Soviet Union and their classification within the genus Lilium. In International Symposium on the Genus Lilium 414; ISHS: Leuven, Belgium, 1994; pp. 133-136.

8. Comber, H.F. A new classification of the genus Lilium. Lily Year Book RHS 1949, 86-105.

9. Endlicher, S.L. Genera Plantarum Secundum Ordines Naturales Disposita: Genera Plantarum ... 1836-1840; Beck: Munich, Germany, 1840; Volume 2.

10. Ikinci, N. Molecular phylogeny and divergence times estimates of Lilium section Liriotypus (Liliaceae) based on plastid and nuclear ribosomal ITS DNA sequence data. Turk. J. Bot. 2011, 35, 319-330.

11. Naqinezhad, A.; Hamzeh'ee, B.; Attar, F. Vegetation-environment relationships in the alderwood communities of Caspian lowlands, N. Iran (toward an ecological classification). Flora-Morphol. Distrib. Funct. Ecol. Plants 2008, 203, 567-577. [CrossRef] 
12. Miller, A.G. Hyrcanian forests, Iran and Azerbaijan. Centres of Plant Diversity, A Guide and Strategy for their Conservation Oxford. IUCN 1994, 1, 343-344.

13. Olteanu, R.; Jipa, D. Dacian Basin environmental evolution during Upper Neogene within the Paratethys domain. Geo-Eco-Marina 2006, 12, 91-105.

14. Tralau, H. Asiatic Dicotyledonous Affinities in the Cainozoic Flora of Europe; Almqvist \& Wiksell: Tofnes, UK, 1963.

15. Zohary, M. Geobotanical Foundation of the Middle East; Fischer-Verlag: Stuttgart, Germany, 1983.

16. Mimaki, Y.; Satou, T.; Kuroda, M.; Sashida, Y.; Hatakeyama, Y. Steroidal saponins from the bulbs of Lilium candidum. Phytochemistry 1999, 51, 567-573. [CrossRef]

17. Fataei, E. Recognition of new habitats of Lilium ledebourii Baker in Northwest Ardabil Province of Iran using GIS technology. In II International Symposium on the Genus Lilium 900; ISHS: Leuven, Belgium, 2010; pp. 65-70.

18. Azadi, P.; Khosh-Khui, M. Micropropagation of Lilium ledebourii (Baker) Boiss as affected by plant growth regulator, sucrose concentration, harvesting season and cold treatments. Electron. J. Biotechnol. 2007, 10, 582-591. [CrossRef]

19. Salehi, M.; Hatamzadeh, A.; Jafarian, V.; Zarre, S. New molecular record and some biochemical features of the rare plant species of Iranian lily (Lilium ledebourii Boiss.). Hortic. Environ. Biotechnol. 2019, 60, 585-593. [CrossRef]

20. Ghanbari, S.; Fakheri, B.A.; Naghavi, M.R.; Mahdinezhad, N. Evaluating phylogenetic relationships in the Lilium family using the ITS marker. J. Plant Biotechnol. 2018, 45, 236-241. [CrossRef]

21. Rockwell, F.F. Complete Book of Lilies; Doubleday: New York, NY, USA, 1961.

22. Woodcock, H.; Stearn, W.T. Lilies of the World; Country Life Limited: London, UK, 1950.

23. Vassou, S.L.; Kusuma, G.; Parani, M. DNA barcoding for species identification from dried and powdered plant parts: A case study with authentication of the raw drug market samples of Sida cordifolia. Gene 2015, 559, 86-93. [CrossRef]

24. Tripathi, A.M.; Tyagi, A.; Kumar, A.; Singh, A.; Singh, S.; Chaudhary, L.B.; Roy, S. The internal transcribed spacer (ITS) region and trnhH-psbA are suitable candidate loci for DNA barcoding of tropical tree species of India. PLoS ONE 2013, 8, e57934. [CrossRef]

25. Chen, C.W.; Huang, Y.M.; Kuo, L.Y.; Nguyen, Q.D.; Luu, H.T.; Callado, J.R.; Farrar, D.R.; Chiou, W.L. trnL-F is a powerful marker for DNA identification of field vittarioid gametophytes (Pteridaceae). Ann. Bot. 2013, 111, 663-673. [CrossRef]

26. Janfaza, S.; Yousefzadeh, H.; Hosseini Nasr, S.M.; Botta, R.; Asadi Abkenar, A.; Torello Marinoni, D. Genetic diversity of Castanea sativa an endangered species in the Hyrcanian forest. Silva Fenn. 2017, 51, 1-15. [CrossRef]

27. White, T.J.; Bruns, T.; Lee, S.; Taylor, J. Amplification and direct sequencing of fungal ribosomal RNA genes for phylogenetics. PCR Protoc. Guide Methods Appl. 1990, 18, 315-322.

28. Johnson, L.A.; Soltis, D.E. matK DNA sequences and phylogenetic reconstruction in Saxifragaceae s. str. Syst. Bot. 1994, 143-156. [CrossRef]

29. Taberlet, P.; Gielly, L.; Pautou, G.; Bouvet, J. Universal primers for amplification of three non-coding regions of chloroplast DNA. Plant Mol. Biol. 1991, 17, 1105-1109. [CrossRef] [PubMed]

30. Sang, T.; Crawford, D.J.; Stuessy, T.F. Chloroplast DNA phylogeny, reticulate evolution, and biogeography of Paeonia (Paeoniaceae). Am. J. Bot. 1997, 84, 1120-1136. [CrossRef] [PubMed]

31. Hayashi1, K.; Kawano2, S. Molecular systematics of Lilium and allied genera (Liliaceae): Phylogenetic relationships among Lilium and related genera based on the rbcL and matK gene sequence data. Plant Species Biol. 2000, 15, 73-93. [CrossRef]

32. Tamura, K.; Stecher, G.; Peterson, D.; Filipski, A.; Kumar, S. MEGA6: Molecular evolutionary genetics analysis version 6.0. Mol. Biol. Evol. 2013, 30, 2725-2729. [CrossRef] [PubMed]

33. Bandelt, H.-J.; Forster, P.; Röhl, A. Median-joining networks for inferring intraspecific phylogenies. Mol. Biol. Evol. 1999, 16, 37-48. [CrossRef] [PubMed]

34. Tamura, K.; Stecher, G.; Kumar, S. MEGA11: Molecular evolutionary genetics analysis version 11. Mol. Biol. Evol. 2021, 38, 3022-3027. [CrossRef] [PubMed]

35. Farris, J.S.; Kallersjo, M.; Kluge, A.G.; Bult, C. Testing Significance of Incongruence; Elsevier: Amsterdam, The Netherlands, 1994.

36. Swofford, D.L. PAUP: Phylogenetic analysis using parsimony version 3.11. In Computer Program Distributed by the Illinois Natural History Survey; University of Illinois at Urbana-Champaign: Champaign, IL, USA, 1993.

37. Kim, J.S.; Kim, J.-H. Updated molecular phylogenetic analysis, dating and biogeographical history of the lily family (Liliaceae: Liliales). Bot. J. Linn. Soc. 2018, 187, 579-593. [CrossRef]

38. Drummond, A.J.; Rambaut, A. BEAST: Bayesian evolutionary analysis by sampling trees. BMC Evol. Biol. 2007, 7, 214. [CrossRef]

39. Drummond, A.J.; Suchard, M.A.; Xie, D.; Rambaut, A. Bayesian phylogenetics with BEAUti and the BEAST 1.7. Mol. Biol. Evol. 2012, 29, 1969-1973. [CrossRef]

40. Rambaut, A. Available online: FigTree.tree.bio.ed.ac.uk/software/figtree (accessed on 12 December 2014).

41. Yu, Y.; Harris, A.J.; Blair, C.; He, X. RASP (Reconstruct Ancestral State in Phylogenies): A tool for historical biogeography. Mol. Phylogenet. Evol. 2015, 87, 46-49. [CrossRef]

42. Baker, J.G. A new synopsis of all the known lilies. Gard. Chron. 1871, 104, 1650.

43. Nishikawa, T.; Okazaki, K.; Uchino, T.; Arakawa, K.; Nagamine, T. A molecular phylogeny of Lilium in the internal transcribed spacer region of nuclear ribosomal DNA. J. Mol. Evol. 1999, 49, 238-249. [CrossRef] [PubMed]

44. Wilson, C.T. The Acceleration of $\beta$-Particles in Strong Electric Fields Such as Those of Thunderclouds. Math. Proc. Camb. Philos. Soc. 1925, 22, 534-538. [CrossRef]

45. McRae, K.; Boisvert, S. Automatic semantic similarity priming. J. Exp. Psychol. Learn. Mem. Cogn. 1998, 24, 558. [CrossRef] 
46. Leslie, A.C. The International Lily Register, Including 17 Additions (1984-1998); Royal Horticultural Society: London, UK, 1982.

47. Tiffney, B.H.; Manchester, S.R. The use of geological and paleontological evidence in evaluating plant phylogeographic hypotheses in the Northern Hemisphere Tertiary. Int. J. Plant Sci. 2001, 162 (Suppl. 6), S3-S17. [CrossRef]

48. İkinci, N.; Oberprieler, C.; Güner, A. On the origin of European lilies: Phylogenetic analysis of Lilium section Liriotypus (Liliaceae) using sequences of the nuclear ribosomal transcribed spacers. Willdenowia 2006, 36, 647-656. [CrossRef]

49. Joger, U.; Fritz, U.; Guicking, D.; Kalyabina-Hauf, S.; Nagy, Z.T.; Wink, M. Relict populations and endemic clades in palearctic reptiles: Evolutionary history and implications for conservation. In Relict Species; Springer: Cham, Switzerland, 2010; pp. 119-143.

50. Khalilzadeh, P.; Rezaei, H.R.; Fadakar, D.; Serati, M.; Aliabadian, M.; Haile, J.; Goshtasb, H. Contact zone of Asian and European wild boar at North West of Iran. PLoS ONE 2016, 11, e0159499.

51. Colagar, A.H.; Yousefzadeh, H.; Shayanmehr, F.; Jalali, S.G.; Zare, H.; Tippery, N.P. Molecular taxonomy of Hyrcanian Alnus using nuclear ribosomal ITS and chloroplast trnH-psbA DNA barcode markers. Syst. Biodivers. 2016, 14, 88-101. [CrossRef]

52. Mostajeran, F.; Yousefzadeh, H.; Davitashvili, N.; Kozlowski, G.; Akbarinia, M. Phylogenetic relationships of Pterocarya (Juglandaceae) with an emphasis on the taxonomic status of Iranian populations using ITS and trnH-psb A sequence data. Plant Biosyst. 2017, 151, 1012-1021. [CrossRef]

53. Manafzadeh, S.; Salvo, G.; Conti, E. A tale of migrations from east to west: The Irano-Turanian floristic region as a source of Mediterranean xerophytes. J. Biogeogr. 2014, 41, 366-379. [CrossRef] 